\title{
Frailty and postoperative complications in older Chinese adults undergoing major thoracic and abdominal surgery
}

This article was published in the following Dove Press journal: Clinical Interventions in Aging

\section{Binru Han \\ Qiuping Li \\ Xi Chen}

Department of Nursing, Xuanwu Hospital, Capital Medical University, Beijing, People's Republic of China
Correspondence: Binru Han Department of Nursing, Xuanwu Hospital, Capital Medical University, Chang chun st.45, Xicheng district, Beijing 100053, People's Republic of China Tel +860 1083198219

Fax +8601083198258

Email kinv246@126.com
Purpose: To determine the association between frailty and postoperative complications in elderly Chinese patients and to determine whether addition of frailty assessment improves the predictive ability of the American Society of Anesthesiologists (ASA) score, Physiological and Operative Severity Score for the Enumeration of Mortality and Morbidity (POSSUM), and Estimation of Physiologic Ability and Surgical Stress (E-PASS) score.

Patients and methods: A prospective cohort study was conducted in a tertiary hospital. Elderly patients undergoing major thoracic or abdominal surgery were included. Frailty phenotype and ASA, POSSUM, and E-PASS scores were assessed. Demographic, preoperative, and surgical variables were extracted from medical records. Primary outcome measure was in-hospital Clavien-Dindo $\geq$ grade II complications. Multiple logistic regression was used to examine the association between frailty and complications. Receiver operating characteristic curves were used to explore the predictive ability of frailty.

Results: Prevalence of frailty was $26.12 \%$. Significant differences were observed between the frail and non-frail groups with respect to age, Activities of Daily Living, Charlson Comorbidity Index, respiratory function, presence of malignancy, serum albumin, prealbumin, and hemoglobin levels $(P<0.05)$. ASA, POSSUM, and E-PASS scores were higher in the frail group. After adjusting for all covariates, frailty was significantly associated with postoperative complications in hospital [odds ratio: 16.59, 95\% CI: 4.56-60.40, $P<0.001$ ]. The area under the curve (AUC) for frailty was 0.762 (95\% CI: $0.703-0.814$ ). The AUC for ASA, POSSUM, and E-PASS for prediction of complications was 0.751 (95\% CI: 0.692-0.804), 0.762 (95\% CI: 0.704-0.814), and 0.824 (95\% CI: 0.771-0.870), respectively. Addition of frailty assessment increased the AUC to 0.858 (95\% CI: $0.808-0.899), 0.842$ (95\% CI: 0.790-0.885), and 0.854 (95\% CI: 0.803-0.896), respectively.

Conclusion: Frailty is an effective predictor of postoperative complications in elderly Chinese patients undergoing major thoracic and abdominal surgery. Frailty assessment can improve the predictive ability of current surgical risk assessment tools. Frailty phenotype should be considered perioperatively. Frailty assessment could also expand the scope for nurses to evaluate patients for safety management.

Keywords: frailty assessment, risk assessment tool, surgery, postoperative complication

\section{Introduction}

Owing to population aging, the proportion of surgeries involving elderly patients has shown an increasing trend. More than $40 \%$ of the patients who undergo surgery in the United States are older than 65 years. ${ }^{1}$ A retrospective study by Kumar showed that thoracic and abdominal surgery account for $54.8 \%$ of all surgeries among the elderly in 
China. $^{2}$ The incidence of adverse postoperative outcomes among older patients is greater than that among younger patients owing to the age-related structural and functional impairment. ${ }^{3}$ The reported incidence rates of postoperative complications among elderly patients undergoing thoracic and abdominal surgery range from $12 \%$ to $47 \%$ and from $13 \%$ to $39 \%$, respectively. ${ }^{4,5}$ Therefore, comprehensive preoperative risk assessment is imperative for older patients undergoing major thoracic or abdominal surgery. Effective assessment tools can help shorten the hospital stay, reduce adverse outcomes, and minimize the medical costs. ${ }^{6}$

Currently, several tools, such as the American Society of Anesthesiologists (ASA) Physical Status Classification System, the Physiological and Operative Severity Score for the Enumeration of Mortality and Morbidity (POSSUM), and Estimation of Physiologic Ability and Surgical Stress (E-PASS), are widely applied for preoperative risk assessment in Asia. However, some of these tools arerelatively complex; in addition, most of these tools are not tailored to the specific characteristics of the elderly patients. ${ }^{7,8,9}$ Several studies have shown that the inclusion of frailty assessment as part of risk assessment may improve the accuracy of surgical risk prediction in the elderly. ${ }^{10,11}$ Frailty is a modern concept in geriatric medicine, it is a medical syndrome characterized by decreased strength and endurance and diminished functional reserve of multiple organ systems, which increases an individual's susceptibility to disability and death. ${ }^{12}$ Frail elderly individuals are more likely to experience adverse surgical outcomes.

Numerous studies have shown that frailty is strongly associated with adverse postoperative outcomes, prolonged length of hospital stay, and disability in older patients. ${ }^{13,14,15,16}$ However, to the best of our knowledge, limited research has been conducted on frailty in Asian settings. Thus, the association between frailty and postoperative complications among elderly Chinese patients undergoing major thoracic and abdominal surgery is not well characterized. In addition, the effect of incorporation of frailty assessment in the currently used preoperative risk assessment tools on their respective predictive ability has not been investigated. Hence, the purpose of this study was to explore the association between frailty and postoperative complications after major thoracic and abdominal surgery. The frailty phenotype was used in this study to investigate (1) the association between frailty and complications after major thoracic and abdominal surgery in Chinese older patients and (2) the effect of the addition of frailty assessment to ASA, POSSUM, and E-PASS scores on their respective predictive ability.

\section{Material and methods Study design and participants}

This was a prospective cohort study of a convenience sample of patients undergoing thoracic and abdominal operations at a tertiary hospital between November 2016 and November 2017. The inclusion criteria were as follows: (1) patients aged $\geq 60$ years undergoing thoracic and abdominal surgery; (2) patients with stable disease status; (3) willingness to participate in this study. Patients suffering from hypothyroidism, Parkinson's disease, or previous stroke, and those with similar debilitating symptoms due to treatment with carbidopa/ levodopa, donepezil, or antidepressants were excluded. Patients with severe cognitive impairment or mental illness, those who were bedridden for a long time, those who were completely incapable of participation, or those who were unable to undergo frailty assessment were also excluded.

The data collection and the measurement of frailty were completed by trained nurses. The postoperative complications during the hospital stay were determined and recorded by clinicians who were not aware of the patients' frailty status. All researchers received training prior to the start of the study. All data were reviewed for quality and consistency. This study was conducted with the permission of the Ethics Committee of the Xuanwu hospital, Capital Medical University. Written informed consent was obtained from all patients prior to their enrolment. Data were analyzed anonymously.

\section{Frailty assessment}

In this study, a trained nurse performed frailty assessment using the definition of the frailty phenotype based on the following five criteria. ${ }^{13,14,15,16}$

- Shrinking: unintentional weight loss of $\geq 5 \%$ in the past year.

- Weakness: based on maximum grip strength of the patient's good hand.

- Self-reported fatigue: based on two self-reported items of the Center for Epidemiological Studies Depression Scale (CES-D): "I felt everything I did was an effort" and "I could not get going".

- Slowness: based on walking 15 feet at normal speed. 
- Low physical activity: based on the International Physical Activity Questionnaire $[<600$ Metabolic Equivalent (MET): minutes over the last week was used to represent low activity level].

Participants can be divided into the following groups: (1) frail if they meet $\geq 3$ criteria, (2) pre-frail if they meet 1-2 criteria, and (3) robust if they meet none of the criteria. ${ }^{17,18}$ However, in this study, the pre-frail and robust groups were combined and collectively referred to as non-frail.

\section{Risk assessment tools}

An anesthesiologist and a clinician who were not aware of the patients' frailty status performed preoperative risk assessment using the ASA, POSSUM, and E-PASS tools. ASA is used to classify the risk of surgery into 1-6 grades according to the physiological state. POSSUM includes 12 physiological variables and 6 surgical severity variables, to calculate the predicted complication rate $(\mathrm{R})$; the following formula is used to calculate the probability of postoperative complications: $\operatorname{lnR} /(1-\mathrm{R})=-5.91+(0.16 \times$ total physiological scores $)+(0.19 \times$ total surgical severity scores $)$. E-PASS involves 6 preoperative risk variables and 3 surgical risk variables to calculate preoperative risk score (PRS), surgical stress score (SSS), and comprehensive risk score (CRS). The formula for CRS (based on PRS and SSS) is as follows: $\mathrm{CRS}=-0.328+0.936 \times \mathrm{PRS}$ $+0.976 \times$ SSS. The higher the CRS value, the greater is the risk of postoperative complications.

\section{Covariates}

Data pertaining to the following potential confounding factors were obtained to determine whether frailty was an independent risk factor for postoperative complications: (1) demographics: age, gender, education level, current smoking and consumption of alcohol status, body mass index (BMI), Activities of Daily Living (ADL), and Charlson Comorbidity Index (CCI); (2) preoperative physiological variables: cardiac function, electrocardiogram (ECG) status, respiratory function, presence of malignancy, blood pressure, and heart rate; (3) preoperative laboratory variables: serum albumin, prealbumin, hemoglobin, white blood cell count, serum urea, creatinine, sodium and potassium levels; and (4) surgical variables: type of surgery, multiple procedures within 30 days, duration of surgery, total blood loss, and abdominal contamination. These data were extracted from the electronic medical records. Data pertaining to demographic characteristics were collected within $24 \mathrm{hr}$ after hospitalization, while those pertaining to preoperative physiological and laboratory variables were collected within $24 \mathrm{hr}$ before surgery; data pertaining to surgical variables were obtained within $24 \mathrm{hr}$ after surgery.

\section{Outcomes}

The outcome measure in this study was in-hospital $\geq$ grade II postoperative complications, according to the ClavienDindo classification standard. The Clavien-Dindo classification standard is a widely applied and validated system for assessment of postoperative complications. ${ }^{19}$ This scoring system classifies complications into 5 classes based on the level of intervention required for treatment of complications. Patients with multiple-grade complications were classified according to the highest-grade complication. The complications were determined and recorded by a clinician who was not aware of the frailty status of the patients.

\section{Statistical analysis}

All statistical analyses were performed using SPSS version 22.0 (IBM Corporation, Armonk, NY, USA) and MedCalc software version 17.11.5 (MedCalc Software, Ostend, Belgium). Data pertaining to continuous variables are presented as mean \pm standard deviation or as median and interquartile range (IQR), and the between-group differences assessed using the independent-sample $t$-test or MannWhitney U test. Categorical variables are presented as percentages, and the between-group differences assessed using the chi-squared test or Fisher's exact test. Univariate and multiple logistic regression were used to explore the association between frailty and adverse outcomes. OR and 95\% CI are reported. Furthermore, receiver operating characteristic (ROC) curve analysis was performed to assess the potential predictive ability of frailty assessment. The HosmerLemeshow goodness-of-fit chi-square test and $R^{2}$ were used to assess the model fit. The area under the ROC curve (AUC) was used to reflect the predictive ability. The $z$ test was used to compare the AUC of different models. $P<0.05$ was considered statistically significant.

\section{Results}

\section{Baseline characteristics}

We assessed 344 Chinese older patients undergoing major thoracic and abdominal surgery. Of these, 245 patients 
qualified the inclusion criteria and were enrolled in the study. The mean age of patients was $67.5 \pm 6.4$ years; males accounted for $50.6 \%$ of patients. The prevalence of frailty in the study population was $26.12 \%$. Significant differences were observed between the frail and non-frail groups with respect to age, CCI, ADL, respiratory function, presence of malignancy, albumin, prealbumin, and hemoglobin level $(P<0.05$ for all). ASA, POSSUM, and E-PASS scores were also significantly different between the frail and non-frail groups $(P<0.05)$ (Table 1).

\section{Frailty and in-hospital postoperative complications}

Among the 245 patients who were included in the final analysis, $25.71 \%(63 / 245)$ had postoperative complications. The number of patients with grade II, III, and grade IV complications was 52,7 , and 3 , respectively; 1 patient died in the postoperative period. The incidence of complications in the frail and non-frail groups was 59.38\% $(38 / 64)$ and $13.81 \%(25 / 181)$, respectively; the betweengroup difference in this respect was statistically significant $(P<0.001)$ (Table S1).

Stratified analysis was performed to clarify the association between frailty and postoperative complications. CCI, BMI, hemoglobin, albumin, prealbumin, surgery duration, respiratory function, and presence of malignancy were used as stratification factors. CCI was divided according to quartiles, while other variables were categorized according to clinically significant cutoff values. The results showed that the differences between the two frailty categories among all the groups were statistically significant $(P<0.05)$ (Table 2).

Univariate logistic analysis showed that the frailty phenotype was associated with postoperative complications $\quad(\mathrm{OR}=9.12,95 \%$ CI: 4.74-17.53) (Table S2). Multiple logistic regression analysis was performed to adjust for potential confounding variables. Model 1 was adjusted for age and gender; Model II was adjusted for current smoking status, BMI, CCI, ADL, respiratory function, ECG, presence of malignancy, heart rate, albumin, prealbumin, hemoglobin, serum sodium, surgery duration, total blood loss, and multiple procedures within 30 days; Model III was adjusted for all covariates. On multiple regression analysis, frailty was found to be a significant predictor of postoperative complications (Table 3). The consistency of the regression results also reflected the robustness of this result.

\section{Predictive ability of frailty}

The AUC for frailty was 0.762 (95\% CI: $0.703-0.814)$. ASA, POSSUM, and E-PASS scores effectively predicted the occurrence of postoperative complications [AUC: $0.751 \quad(95 \% \quad$ CI: $\quad 0.692-0.804), \quad 0.762 \quad(95 \% \quad$ CI: 0.704-0.814), and 0.824 (95\% CI: $0.771-0.870)$, respectively]. Addition of the frailty assessment improved the predictive ability of ASA, POSSUM, and E-PASS scores for postoperative complications, with the AUC rising to $0.858 \quad(95 \% \quad$ CI: $\quad 0.808-0.899), \quad 0.842 \quad(95 \% \quad$ CI: $0.790-0.885$ ), and 0.854 (95\% CI: $0.803-0.896)$, respectively (Figure 1). Simultaneously, the model fitting results after addition of frailty assessment to the ASA, POSSUM, and E-PASS scores were better than those for the surgical risk assessment scores alone (Table 4).

\section{Discussion}

In this study, we explored the association between frailty and postoperative complications after major thoracic and abdominalsurgery in Chinese older patients, in addition, we assessed the effect of the addition of frailty assessment on the predictive ability of the ASA, POSSUM, and E-PASS scores. We found that frailty was a significant predictor of postoperative complications; in addition, frailty assessment showed a moderate predictive ability for postoperative complications. Our results suggest that the addition of frailty assessment to ASA, POSSUM, and E-PASS scores may improve the predictive ability of these tools.

In the present study, the prevalence of frailty among older Chinese patients undergoing major thoracic and abdominal surgery $(26.12 \%)$ was comparable to that reported by Hewittet al (28\%). ${ }^{20}$ However, this prevalence is higher than that reported among community-dwelling older people in China (range, 7.4\%-14.2\%). ${ }^{21,22}$ The increased prevalence in the current study reflects the different study population; hospitalized elderly patients tend to have decreased functional reserve and decreased the ability to deal with disease-related stress, and patients with concurrent thoracic and abdominal diseases are at a higher risk of poor nutritional status. ${ }^{23}$ Therefore, the patients were more likely to be frail.

In this study, frailty was an independent predictor of postoperative complications in elderly Chinese patients undergoing major thoracic and abdominal surgery (OR=16.59, 95\% CI: 4.56-60.40, $P<0.001$ ), and the results of the stratified analysis were consistent with this finding. Frailty assessment may be advantageous in 
Table I Comparison of baseline characteristics between frail and non-frail participants

\begin{tabular}{|c|c|c|c|c|}
\hline Characteristic & Overall $(N=245)$ & Non-frail $(N=\mid 81)$ & Frail $(N=64)$ & $P$-value \\
\hline \multicolumn{5}{|l|}{ Demographic } \\
\hline Age, mean $\pm S D$ (years) & $67.5 \pm 6.4$ & $66.4 \pm 5.5$ & $70.7 \pm 7.5$ & $<0.001$ \\
\hline Male, $n$ (\%) & $124(50.6)$ & $93(51.4)$ & 31 (48.4) & 0.686 \\
\hline Education, $n(\%)$ & & & & 0.639 \\
\hline Illiterate & $29(11.8)$ & $21(11.6)$ & $8(12.5)$ & \\
\hline Elementary school & $27(11.0)$ & $18(9.9)$ & $9(14.1)$ & \\
\hline Junior/senior high school & $148(60.4)$ & $109(60.2)$ & $39(60.9)$ & \\
\hline Undergraduate & $41(16.7)$ & $33(18.3)$ & $8(12.5)$ & \\
\hline Type of surgery, n (\%) & & & & 0.294 \\
\hline Abdominal & |2| (49.4) & $93(51.4)$ & $28(43.8)$ & \\
\hline Thoracic & $124(50.6)$ & $88(48.6)$ & $36(56.2)$ & \\
\hline Presence of malignancy, $n(\%)$ & & & & 0.007 \\
\hline None & $134(54.7)$ & $109(60.2)$ & $25(39.1)$ & \\
\hline Primary only & $90(36.7)$ & $56(30.9)$ & $34(53.1)$ & \\
\hline Metastases & $21(8.6)$ & $16(8.9)$ & $5(7.8)$ & \\
\hline Current smoker, $n$ (\%) & $56(22.9)$ & $40(22.1)$ & $16(25.0)$ & 0.635 \\
\hline Current drinker, $n(\%)$ & $50(20.4)$ & $39(21.5)$ & II (17.2) & 0.457 \\
\hline $\mathrm{BMI}$, mean $\pm \mathrm{SD}$ & $24.4 \pm 3.3$ & $24.7 \pm 3.0$ & $23.6 \pm 3.7$ & 0.02 \\
\hline $\mathrm{CCl}$, mean $\pm \mathrm{SD}$ & $2.1 \pm 1.8$ & $1.9 \pm 1.8$ & $2.7 \pm 1.7$ & 0.0085 \\
\hline$A D L$, mean $\pm S D$ & $95.7 \pm 8.4$ & $97.5 \pm 6.4$ & $90.7 \pm 11.1$ & $<0.001$ \\
\hline \multicolumn{5}{|l|}{ Preoperative variables } \\
\hline Normal cardiac function, $n(\%)$ & $138(56.3)$ & $107(59.1)$ & $31(48.4)$ & 0.139 \\
\hline Normal respiratory function, $n(\%)$ & $199(81.2)$ & $153(84.5)$ & $46(71.9)$ & 0.035 \\
\hline Normal electrocardiogram, $n$ (\%) & $164(66.9)$ & $126(69.6)$ & $38(59.4)$ & 0.135 \\
\hline Systolic pressure, mean \pm SD & $127.8 \pm 14.8$ & $127.2 \pm 14.0$ & $129.4 \pm 16.7$ & 0.36 \\
\hline Heart rate, mean $\pm S D$ & $75.3 \pm 7.3$ & $75.2 \pm 7.3$ & $75.4 \pm 7.5$ & 0.665 \\
\hline Albumin, mean $\pm S D$ & $37.6 \pm 4.2$ & $38.3 \pm 4.0$ & $35.7 \pm 4.3$ & $<0.001$ \\
\hline Prealbumin, mean $\pm S D$ & $220.8 \pm 67.1$ & $229.7 \pm 63.4$ & $195.6 \pm 71.0$ & $<0.001$ \\
\hline Hemoglobin, mean $\pm S D$ & $13.0 \pm 1.7$ & $13.3 \pm 1.4$ & $12.0 \pm 2.1$ & $<0.001$ \\
\hline White blood cells, mean $\pm S D$ & $5.9 \pm 1.9$ & $5.9 \pm 2.0$ & $5.9 \pm 1.6$ & 0.508 \\
\hline Urea, mean $\pm S D$ & $5.2 \pm 1.5$ & $5.2 \pm 1.3$ & $5.2 \pm 1.9$ & 0.527 \\
\hline Creatinine, mean $\pm \mathrm{SD}$ & $66.0 \pm 17.3$ & $66.0 \pm 15.3$ & $66.2 \pm 22.1$ & 0.955 \\
\hline Sodium, mean $\pm S D$ & $140.8 \pm 2.7$ & $140.9 \pm 2.5$ & $140.6 \pm 3.3$ & 0.879 \\
\hline Potassium, mean $\pm \mathrm{SD}$ & $4.1 \pm 0.4$ & $4.1 \pm 0.4$ & $4.1 \pm 0.4$ & 0.815 \\
\hline \multicolumn{5}{|l|}{ Surgical variables } \\
\hline Surgery duration, median (IQR) & $91(53,179)$ & $81(47,173.5)$ & $119(65,222.25)$ & 0.003 \\
\hline Total blood loss, median (IQR) & $10(5,80)$ & $10(5,50)$ & $20(5,100)$ & 0.408 \\
\hline \multicolumn{5}{|c|}{ Multiple procedures within 30 days, $n$ (\%) } \\
\hline No & $235(95.9)$ & $176(97.2)$ & $59(92.2)$ & 0.165 \\
\hline Yes & $10(4.1)$ & $5(2.8)$ & $5(7.8)$ & \\
\hline No abdominal contamination, $n(\%)$ & $244(99.6)$ & $182(100)$ & $62(98.4)$ & 0.586 \\
\hline \multicolumn{5}{|l|}{ Risk assessment tools } \\
\hline ASA, $n(\%)$ & & & & $<0.001$ \\
\hline 1 & $2(0.8)$ & $\mathrm{I}(0.6)$ & I ( 1.6$)$ & \\
\hline 2 & $145(59.2)$ & $120(66.3)$ & $25(39.1)$ & \\
\hline 3 & $95(38.8)$ & $60(33.1)$ & $35(54.7)$ & \\
\hline 4 & $3(1.2)$ & $0(0.0)$ & $3(4.7)$ & \\
\hline POSSUM, mean $\pm S D$ & $0.3 \pm 0.2$ & $0.3 \pm 0.2$ & $0.5 \pm 0.2$ & $<0.001$ \\
\hline E-PASS, mean $\pm S D$ & $-0.1 \pm 1.6$ & $-0.2 \pm 1.8$ & $0.2 \pm 0.3$ & $<0.001$ \\
\hline
\end{tabular}

Abbreviations: BMI, body mass index; CCl, Charlson Comorbidity Index; ADL, Activities of Daily Living; ASA, American Association of Anesthesiologists; POSSUM, Physiological and Operative Severity Score for the Enumeration of Mortality and Morbidity; E-PASS, Estimation of Physiologic Ability and Surgical Stress; SD, standard deviation; IQR, interquartile range. 
Table 2 Stratified analysis of association between frailty category and in-hospital postoperative complications

\begin{tabular}{|c|c|c|c|}
\hline Subgroup & No. of patients & OR (95\% Cl) & $P$-value \\
\hline \multicolumn{4}{|l|}{ Hemoglobin } \\
\hline Male < $12 \mathrm{~g} / \mathrm{L}$, Female <II g/L & 37 & $4.11(1.01,16.83)$ & 0.0490 \\
\hline Male $12-16 \mathrm{~g} / \mathrm{L}$, Female $1 \mathrm{I}-15 \mathrm{~g} / \mathrm{L}$ & 198 & $7.93(3.66,17.18)$ & $<0.001$ \\
\hline Male $>16 \mathrm{~g} / \mathrm{L}$, Female $>15 \mathrm{~g} / \mathrm{L}$ & 10 & $\mathrm{~N} / \mathrm{A}$ & $\mathrm{N} / \mathrm{A}$ \\
\hline \multicolumn{4}{|l|}{ Albumin } \\
\hline$<35 \mathrm{~g} / \mathrm{L}$ & 61 & $25.67(6.08,108.28)$ & $<0.001$ \\
\hline$\geq 35 \mathrm{~g} / \mathrm{L}$ & 184 & $5.17(2.30,11.64)$ & $<0.001$ \\
\hline \multicolumn{4}{|l|}{ BMI } \\
\hline$<18.5$ & 8 & $\mathrm{~N} / \mathrm{A}$ & $\mathrm{N} / \mathrm{A}$ \\
\hline $18.5-23.9$ & 116 & $6.73(2.68,16.9)$ & $<0.001$ \\
\hline$>23.9$ & 121 & I2.83 (4.7|, 34.97) & $<0.001$ \\
\hline \multicolumn{4}{|l|}{ Surgery duration } \\
\hline$<90 \min$ & 119 & $19.2(3.54,104.08)$ & $<0.001$ \\
\hline$\geq 90 \mathrm{~min}$ & 126 & $7.59(3.29,17.52)$ & $<0.001$ \\
\hline \multicolumn{4}{|l|}{ Respiratory function } \\
\hline Normal & 199 & $6.65(3.16,14.01)$ & $<0.001$ \\
\hline Abnormal & 46 & $23.00(4.77,110.8)$ & $<0.001$ \\
\hline \multicolumn{4}{|l|}{ Presence of malignancy } \\
\hline None & 134 & $12.60(4.53,35.05)$ & $<0.001$ \\
\hline Primary only & 90 & $5.34(2.11,13.53)$ & $<0.001$ \\
\hline Metastases & 21 & $10.50(1.03,107.17)$ & 0.0473 \\
\hline \multicolumn{4}{|l|}{ Prealbumin } \\
\hline$<170 \mathrm{mg} / \mathrm{L}$ & 55 & $12.28(3.39,44.43)$ & $<0.001$ \\
\hline$\geq 170 \mathrm{mg} / \mathrm{L}$ & 190 & $7.18(3.30,15.66)$ & $<0.001$ \\
\hline \multicolumn{4}{|l|}{$\mathrm{CCl}$} \\
\hline$<3$ & 169 & II.47 (4.83, 27.26) & $<0.001$ \\
\hline$\geq 3$ & 76 & $6.59(2.26,19.27)$ & $<0.001$ \\
\hline
\end{tabular}

Abbreviations: BMI, body mass index; $\mathrm{CCl}$, Charlson Comorbidity Index; N/A, not applicable.

Table 3 Multiple logistic regression analysis of in-hospital postoperative complications

\begin{tabular}{|l|l|l|l|l|}
\hline & $\begin{array}{l}\text { Non-adjusted OR (95\%Cl) } \\
\text { P-value }\end{array}$ & $\begin{array}{l}\text { Model I OR (95\% CI) } \\
\text { P-value }\end{array}$ & $\begin{array}{l}\text { Model II OR (95\% CI) } \\
\text { P-value }\end{array}$ & $\begin{array}{l}\text { Model III OR (95\% CI) } \\
\text { P-value }\end{array}$ \\
\hline Frailty & $4.77,(2.16,10.55),<0.00 I$ & $5.83,(2.52,13.53),<0.00 I$ & $10.31,(3.55,129.96),<0.00 I$ & $16.59,(4.56,60.40),<0.00 I$ \\
ASA & $3.86,(1.73,8.62),<0.001$ & $3.84,(1.70,8.69), 0.001$ & $5.09,(1.98,13.07),<0.00 I$ & $6.20,(2.02,19.04),<0.00 I$ \\
POSSUM & $14.88,(2.05,108.03), 0.008$ & $21.19,(2.70,166.52), 0.004$ & $8.89,(0.09,844.48), 0.347$ & $1.29,(0.01,564.93), 0.934$ \\
E-PASS & $6.78,(1.12,40.87), 0.037$ & $7.65,(1.24,47.04), 0.028$ & $1.06,(0.28,3.98), 0.936$ & $1.23,(0.06,27.35), 0.898$ \\
\hline
\end{tabular}

Notes: Model I: frailty + age and gender; Model II: frailty + current smoking status, BMI, CCI, ADL, respiratory function, electrocardiogram, presence of malignancy, heart rate, albumin, prealbumin, hemoglobin, sodium, surgery duration, total blood loss, and multiple procedures within 30 days; Model III: frailty + all other covariates.

Abbreviations: ASA, American Association of Anesthesiologists; POSSUM, Physiological and Operative Severity Score for the Enumeration of Mortality and Morbidity; E-PASS, Estimation of Physiologic Ability and Surgical Stress.

clinical practice. A retrospective study of elderly patients undergoing lung transplantation found no significant association of frailty with the duration of postoperative ventilator use or duration of stay in the intensive care unit; however, frailty was associated with a significantly greater risk of postoperative death [adjusted HR: 2.24]. ${ }^{24}$ In another study, preoperative surgical risk score of frail elderly patients undergoing emergency cholecystectomy was significantly greater than that of non-frail patients, ${ }^{25}$ which is consistent with the results of our study. Our 

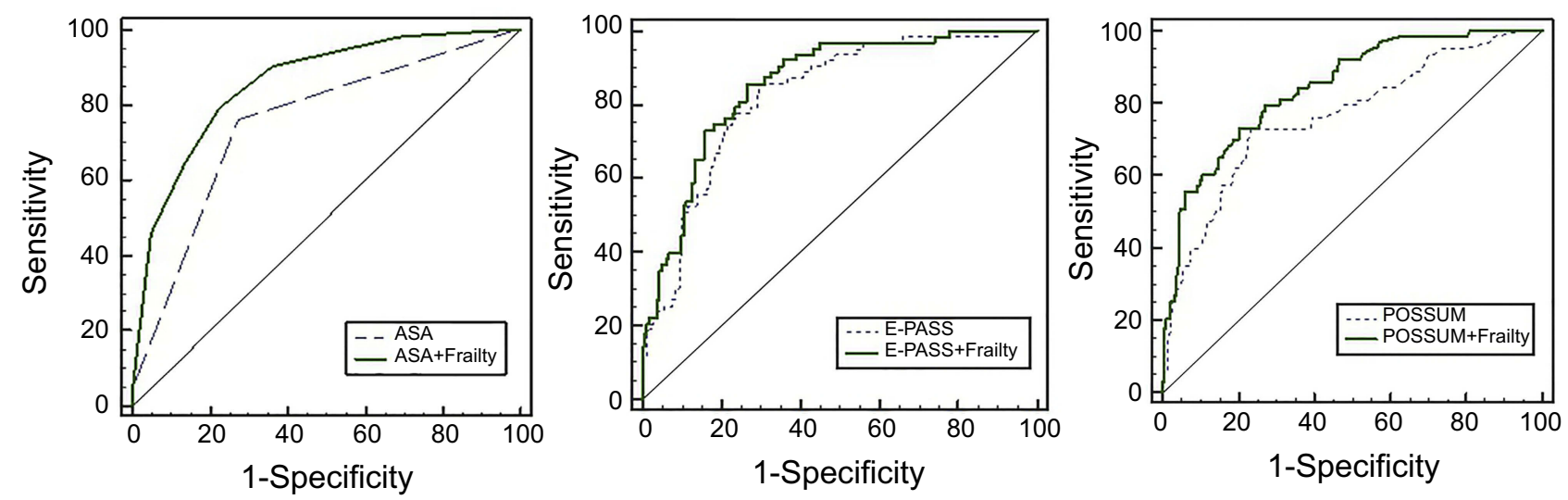

Figure I Receiver operating characteristic (ROC) curves showing the predictive ability of risk assessment tools and frailty assessment.

Table 4 Performance of risk assessment tools and frailty assessment in predicting postoperative complications

\begin{tabular}{|c|c|c|c|c|c|}
\hline & $\begin{array}{l}\text { Cox \& Snell } \\
\mathbf{R}^{2}\end{array}$ & $\begin{array}{l}\text { Nagelkerke } \\
\mathbf{R}^{2}\end{array}$ & $\begin{array}{l}\text { Hosmer-Lemeshow } \chi^{2} \\
\text { (P-value) }\end{array}$ & $\operatorname{AUC}(95 \% \mathrm{Cl})$ & $\begin{array}{l}\triangle \text { AUC } \\
\text { (P-value) }\end{array}$ \\
\hline Frailty & 0.176 & 0.259 & N/A & $0.762(0.703,0.814)$ & $\mathrm{N} / \mathrm{A}$ \\
\hline ASA & 0.187 & 0.274 & $0.045(0.832)$ & $0.75 \mathrm{I}(0.692,0.804)$ & $0.107(<0.001)$ \\
\hline ASA + Frailty & 0.301 & 0.442 & $1.605(0.952)$ & $0.858(0.808,0.899)$ & \\
\hline POSSUM & 0.169 & 0.248 & $15.758(0.046)$ & $0.762(0.704,0.814)$ & $0.080(0.0044)$ \\
\hline $\begin{array}{l}\text { POSSUM + } \\
\text { Frailty }\end{array}$ & 0.268 & 0.393 & $9.360(0.313)$ & $0.842(0.790,0.885)$ & \\
\hline E-PASS & 0.222 & 0.326 & $8.049(0.429)$ & $0.824(0.77 \mathrm{I}, 0.870)$ & $0.030(0.1095)$ \\
\hline E-PASS + Frailty & $0.28 \mathrm{I}$ & 0.413 & |3.98| (0.082) & $0.854(0.803,0.896)$ & \\
\hline
\end{tabular}

Abbreviations: ASA, American Association of Anesthesiologists; POSSUM, Physiological and Operative Severity Score for the Enumeration of Mortality and Morbidity; E-PASS, Estimation of Physiologic Ability and Surgical Stress; AUC, area under the curve; N/A, not applicable.

research corroborates these findings and suggests that preoperative frailty assessment may confer an advantage in Chinese elderly patients undergoing major thoracic or abdominal surgery. Frailty may help explain the differences in postoperative recovery of elderly patients undergoing the same surgery at the same age. However, there is currently no consensus on the gold standard for assessment of frailty, studies have employed different tools for frailty assessment, such as frailty index, Tilburg frailty indicator, and single physical indicator. Some studies have assessed the use of more objective methods for frailty assessment. For example, computed tomography (CT) has been used to assess sarcopenia as a parameter of frailty in elderly individuals; the results indicated that $\mathrm{CT}$ evaluation of muscles may be incorporated in the preoperative surgical risk assessment. ${ }^{26}$ Due to resource constraints, we did not employ CT evaluation; instead, we used the frailty phenotype, which has been widely used in clinical studies. ${ }^{27}$ Frailty phenotype includes both subjective and objective indicators and is a relatively simple and convenient tool; this study provides evidence for the practical value of the frailty phenotype.

ASA, POSSUM, and E-PASS are widely used preoperative risk assessment tools, and many studies have confirmed their ability to predict adverse surgical outcomes. ${ }^{28-30}$ However, these generic risk assessment tools are not tailored to the specific characteristics of the elderly, who represent a special group. Our study showed that incorporation of frailty assessment may increase the predictive ability of current risk assessment tools; the AUC for ASA, POSSUM, and E-PASS increased by 0.106, 0.08, and 0.03 , respectively, upon addition of frailty assessment. Makary et al showed that frailty increased the ability of ASA, Lee, and Eagle scores to predict the risk of complications. The AUC for postoperative complications predicted by ASA, Lee, and Eagle scores was 0.708, 0.715, and 0.732 , respectively. After addition of frailty assessment, the AUC increased to 0.748, 0.740, and 0.753, respectively. ${ }^{11}$ Sharrock et al reported that the combination of frailty assessment and Portsmouth $(P)$-POSSUM might 
be a better way to identify elderly patients who are at a high risk of mortality. ${ }^{31}$ Nevertheless, the previous studies lacked data on Asian populations and did not simultaneously compare the predictive ability of multiple instruments for risk assessment. The present study explored the value of frailty assessment in an Asian population. In addition, we performed a detailed stratified analysis and ROC curve analysis to provide more robust results. Frailty assessment effectively improved the predictive ability of multiple risk assessment tools; therefore, it may improve clinical decision-making and the development of treatment plans. Additionally, frailty is a dynamic process that can be reversed through targeted interventions. Previous studies have shown that exercise, diet, and medication can effectively slow down or ameliorate frailty. ${ }^{32}$ Future studies should involve the development of frailty response measures suitable for elderly patients undergoing surgery, so as to improve the perioperative safety of these patients.

There are several limitations in this study. Firstly, this study mainly explored the association between frailty and short-term adverse postoperative outcomes. Long-term outcomes were not assessed. Secondly, medical personnel were not informed about the frailty status of the patients. The individual perceptions of these medical personnel regarding each patient's frailty status may have affected their formulation of perioperative care plans. Thirdly, the study involved a single center. Multicenter research should be conducted to study the causal mechanisms and the external manifestations of frailty in the future.

\section{Conclusion}

In this study, frailty was a significant predictor of postoperative complications in elderly Chinese patients undergoing major thoracic and abdominal surgery. Incorporation of frailty assessment in perioperative risk assessment may improve the ability of ASA, POSSUM, and E-PASS scores to predict postoperative complications, which can facilitate treatment planning and forewarn about postoperative risks. Frailty assessment could also expand the scope for nurses to evaluate patients, thus further improving the ability of nurses for safety management.

\section{Acknowledgments}

We thank all the staff of general surgery department, Xuanwu Hospital, Capital Medical University, for their cooperation and the anonymous reviewers. This work was supported by the Beijing Municipal Administration of Hospitals Clinical Medicine Development of Special Funding Support (ZYLX201706).

\section{Author contributions}

All authors contributed to data analysis, drafting or revising the article, gave final approval of the version to be published, and agree to be accountable for all aspects of the work.

\section{Disclosure}

The authors report no conflicts of interest in this work.

\section{References}

1. Margaret Jean Hall PD, Carol J, DeFrances PD, Sonja N, Williams MPH, Aleksandr Golosinskiy MS. National Hospital discharge survey: 2007 summary. Natl Health Stat Report. 2010;(29):1-24.

2. Kumar DS. An Evaluation of Perioperative Events in Geriatric Surgical Patients. Shang Hai: Fudan University; 2013.

3. Groban L, Kim S, Brooks A. Preoperative assessment of the older surgical patient: honing in on geriatric syndromes. Clin Interv Aging. 2014;10:13-27. doi:10.2147/CIA.S75285

4. Mosquera C, Spaniolas K, Fitzgerald TL. Impact of frailty on surgical outcomes: the right patient for the right procedure. Surgery. 2016;160 (2):272-280. doi:10.1016/j.surg.2016.04.030

5. Revenig LM, Canter DJ, Kim S, et al. Report of a simplified frailty score predictive of short-term postoperative morbidity and mortality. $J$ Am Coll Surg. 2015;220(5):904-911. doi:10.1016/j.jamcollsurg.2015.01.053

6. Kappen TH, Peelen LM. Prediction models: the right tool for the right problem. Curr Opin Anaesthesiol. 2016;29(6):717-726. doi:10.1097/ACO.0000000000000386

7. Daabiss M. American Society of Anaesthesiologists physical status classification. Indian J Anaesth. 2011;55(2):111-115. doi:10.4103/ 0019-5049.79879

8. Copeland GP, Jones D, Walters M. POSSUM: a scoring system for surgical audit. Br J Surg. 1991;78(3):355-360.

9. Haga Y, Ikei S, Ogawa M. Estimation of physiologic ability and surgical stress (E-PASS) as a new prediction scoring system for postoperative morbidity and mortality following elective gastrointestinal surgery. Jpn J Surg. 1999;29(3):219-225.

10. Gleason LJ, Benton EA, Alvarez-Nebreda ML, Weaver MJ, Harris MB, Javedan H. FRAIL questionnaire screening tool and short-term outcomes in geriatric fracture patients. J Am Med Dir Assoc. 2017;18(12):1082-1086. doi:10.1016/j.jamda.2017.07.005

11. Makary MA, Segev DL, Pronovost PJ, et al. Frailty as a predictor of surgical outcomes in older patients. J Am Coll Surg. 2010;210 (6):901-908. doi:10.1016/j.jamcollsurg.2010.01.028

12. Morley JE, Vellas B, van Kan GA, et al. Frailty consensus: a call to action. J Am Med Dir Assoc. 2013;6(14):392-397. doi:10.1016/j. jamda.2013.03.022

13. Oakland K, Nadler R, Cresswell L, Jackson D, Coughlin PA. Systematic review and meta-analysis of the association between frailty and outcome in surgical patients. Ann R Coll Surg Engl. 2016;98(2):80-85. doi:10.1308/rcsann.2016.0048

14. Shen Y, Hao Q, Zhou J, Dong B. The impact of frailty and sarcopenia on postoperative outcomes in older patients undergoing gastrectomy surgery: a systematic review and meta-analysis. BMC Geriatr. 2017;17(1):188. doi:10.1186/s12877-017-0515-3 
15. Kojima G. Frailty defined by FRAIL scale as a predictor of mortality: a systematic review and meta-analysis. J Am Med Dir Assoc. 2018;19 (6):480-483. doi:10.1016/j.jamda.2018.04.006

16. Kleczynski P, Dziewierz A, Bagienski M, et al. Impact of frailty on mortality after transcatheter aortic valve implantation. Am Heart $J$. 2017;185:52-58. doi:10.1016/j.ahj.2016.12.005

17. Fried LP, Tangen CM, Walston J, et al. Frailty in older adults: evidence for a phenotype. J Gerontol A Biol Sci Med Sci. 2001;56 (3):146-156. doi:10.1093/gerona/56.3.M146

18. Chang CI, Chan DC, Kuo KN, Hsiung CA, Chen CY. Prevalence and correlates of geriatric frailty in a northern Taiwan community. $J$ Formos Med Assoc. 2011;110(4):247-257. doi:10.1016/S0929-6646(11)60037-5

19. Clavien PA, Barkun J, de Oliveira ML, et al. The Clavien-Dindo classification of surgical complications: five-year experience. Ann Surg. 2009;250(2):187-196. doi:10.1097/SLA.0b013e3181b13ca2

20. Hewitt J, Moug SJ, Middleton M, Chakrabarti M, Stechman MJ, McCarthy K. Prevalence of frailty and its association with mortality in general surgery. Am J Surg. 2015;209(2):254-259. doi:10.1016/j. amjsurg.2014.05.022

21. Chun-Xia L, Hong-Mei MA, Xu XU, Jiao-Jiao WU. Prevalence of frailty in Chinese community-dwelling older adults: a meta-analysis. Occup Health. 2017;33(20):2767-2770.

22. Llibre RJ, Prina AM, Acosta D, et al. The prevalence and correlates of frailty in urban and rural populations in Latin America, China, and India: A 10/66 population-based survey. $J$ Am Med Dir Assoc. 2018;19(4):287-295. doi:10.1016/j.jamda.2017.09.026

23. Huan X, Xuejiao Z, Xin Y, Hongyuan C, Jifang M, Mingwei Z. Correlation between the risk of falling and nutritional status in elderly surgical patients. Chin J Clin Nutr. 2016;24(1):28-32.

24. Wilson ME, Vakil AP, Kandel P, Undavalli C, Dunlay SM, Kennedy CC. Pretransplant frailty is associated with decreased survival after lung transplantation. $J$ Heart Lung Transplant. 2016;35 (2):173-178. doi:10.1016/j.healun.2015.10.014
25. Lorenzon L, Costa G, Massa G, Frezza B, Stella F, Balducci G. The impact of frailty syndrome and risk scores on emergency cholecystectomy patients. Surg Today. 2017;47(1):74-83. doi:10.1007/ s00595-016-1361-1

26. Kleczynski P, Tokarek T, Dziewierz A, et al. Usefulness of psoas muscle area and volume and frailty scoring to predict outcomes after transcatheter aortic valve implantation. Am J Cardiol. 2018;122 (1):135-140. doi:10.1016/j.amjcard.2018.03.020

27. Buta BJ, Walston JD, Godino JG, et al. Frailty assessment instruments: systematic characterization of the uses and contexts of highly-cited instruments. Ageing Res Rev. 2016;26:53-61. doi:10.1016/j.arr.2015.12.003

28. Jering MZ, Marolen KN, Shotwell MS, Denton JN, Sandberg WS, Ehrenfeld JM. Combining the ASA physical classification system and continuous intraoperative surgical apgar score measurement in predicting postoperative risk. J Med Syst. 2015;39(11):147. doi:10.1007/ s10916-015-0332-1

29. Gonzalez-Martinez S, Martin-Baranera M, Marti-Sauri I, BorrellGrau N, Pueyo-Zurdo JM. Comparison of the risk prediction systems POSSUM and P-POSSUM with the surgical risk scale: a prospective cohort study of 721 patients. Int J Surg. 2016;29:19-24. doi:10.1016/ j.ijsu.2016.03.005

30. Tominaga T, Takeshita H, Takagi $\mathrm{K}$, et al. E-PASS score as a useful predictor of postoperative complications and mortality after colorectal surgery in elderly patients. Int $J$ Colorectal Dis. 2016;31 (2):217-225. doi:10.1007/s00384-015-2456-7

31. Sharrock AE, McLachlan J, Chambers R, Bailey IS, Kirkby-Bott J. Emergency abdominal surgery in the elderly: can we predict mortality? World J Surg. 2017;41(2):402-409. doi:10.1007/s00268-016-3751-3

32. Dent E, Lien C, Lim WS, et al. The Asia-Pacific clinical practice guidelines for the management of frailty. $J$ Am Med Dir Assoc. 2017;18(7):564-575. doi:10.1016/j.jamda.2017.04.018 


\section{Supplementary materials}

Table SI Association between frailty category and in-hospital postoperative complications

\begin{tabular}{|l|l|l|l|}
\hline Complications/classification & Frail $(\mathbf{N}=\mathbf{6 4})$ & Non-frail $(\mathbf{N}=\mathbf{l} \mathbf{8 I})$ & $\mathbf{P}$-value \\
\hline Complications, $n$ & 38 & 25 & $<0.001$ \\
\hline Clavien-Dindo classification, $n$ & & & \\
Grade 2 & 33 & 19 & 0.548 \\
Grade 3 & 3 & 4 & \\
Grade 4 & 2 & 1 & \\
Grade 5 & 0 & 1 & \\
\hline
\end{tabular}

Table S2 Univariate logistic regression of postoperative complications in hospital

\begin{tabular}{|c|c|c|}
\hline Characteristic & OR $(95 \% \mathrm{Cl})$ & $P$-value \\
\hline \multicolumn{3}{|l|}{ Demographics } \\
\hline \multicolumn{3}{|l|}{ Frailty status } \\
\hline Non-frail & 1.00 & $\mathrm{~N} / \mathrm{A}$ \\
\hline Frail & $9.12(4.74,17.53)$ & $<0.0001$ \\
\hline Age & $1.04(0.99,1.08)$ & 0.1048 \\
\hline \multicolumn{3}{|l|}{ Gender } \\
\hline Male & 1.00 & $\mathrm{~N} / \mathrm{A}$ \\
\hline Female & $0.91(0.5 \mathrm{I}, \mathrm{I} .6 \mathrm{I})$ & 0.7446 \\
\hline \multicolumn{3}{|l|}{ Education } \\
\hline illiterate & 1.00 & $\mathrm{~N} / \mathrm{A}$ \\
\hline Elementary & I.II $(0.35,3.53)$ & 0.8657 \\
\hline junior/senior high school & $0.91(0.37,2.22)$ & 0.8302 \\
\hline Undergraduate & $0.74(0.25,2.25)$ & 0.5887 \\
\hline \multicolumn{3}{|l|}{ Type of surgery } \\
\hline Abdominal & 1.00 & $\mathrm{~N} / \mathrm{A}$ \\
\hline Thoracic & $1.31(0.73,2.32)$ & 0.3632 \\
\hline \multicolumn{3}{|l|}{ Presence of malignancy } \\
\hline None & 1.00 & $\mathrm{~N} / \mathrm{A}$ \\
\hline Primary only & $2.78(1.51,5.14)$ & 0.0011 \\
\hline Metastases & I.43 $(0.48,4.29)$ & 0.5209 \\
\hline Current smoking status & $1.89(0.99,3.59)$ & 0.0533 \\
\hline Current drinking status & $1.31(0.66,2.61)$ & 0.4379 \\
\hline BMI & $0.86(0.78,0.95)$ & 0.0036 \\
\hline $\mathrm{CCl}$ & $1.19(1.02,1.38)$ & 0.0255 \\
\hline$A D L$ & $0.97(0.94,1.00)$ & 0.0319 \\
\hline \multicolumn{3}{|l|}{ Peroperative variables } \\
\hline \multicolumn{3}{|l|}{ Cardiac function } \\
\hline Normal & 1.00 & $N / A$ \\
\hline Abnormal & $1.04(0.59,1.86)$ & 0.8862 \\
\hline \multicolumn{3}{|l|}{ Respiratory function } \\
\hline Normal & 1.00 & N/A \\
\hline Abnormal & $2.79(1.42,5.47)$ & 0.0028 \\
\hline
\end{tabular}


Table S2 (Continued).

\begin{tabular}{|l|l|l|}
\hline Characteristic & OR (95\% CI) & P-value \\
\hline Electrocardiogram & 1.00 & N/A \\
$\quad$ Normal & $2.13(1.18,3.85)$ & 0.0028 \\
Systolic pressure & $1.00(0.98,1.02)$ & 0.9887 \\
Heart rate & $1.04(1.00,1.08)$ & 0.0776 \\
Albumin & $0.87(0.81,0.94)$ & 0.0002 \\
Prealbumin & $0.99(0.99,1.0)$ & 0.0005 \\
Hemoglobin & $0.65(0.54,0.78)$ & $<0.0001$ \\
White Blood Cell & $0.95(0.81,1.11)$ & 0.5193 \\
Urea & $1.14(0.95,1.39)$ & 0.1667 \\
Creatinine & $0.99(0.98,1.01)$ & 0.4933 \\
Sodium & $0.89(0.81,0.99)$ & 0.0361 \\
Potassium & $0.64(0.30,1.35)$ & 0.2379 \\
\hline Surgical variables & & $<0.0001$ \\
Surgery duration & $1.01(1.01,1.02)$ & $<0.0001$ \\
Total blood loss & $1.01(1.01,1.01)$ & \\
\hline Multiple procedures within 30 days & & \\
0 & 1.00 & \\
I & $4.68(1.28,17.19)$ & \\
\hline Abbrevia & \\
\hline
\end{tabular}

Abbreviations: BMI, body mass index; $\mathrm{CCl}$, Charlson Comorbidity Index; ADL, Activities of Daily Living.

Clinical Interventions in Aging

\section{Publish your work in this journal}

Clinical Interventions in Aging is an international, peer-reviewed journal focusing on evidence-based reports on the value or lack thereof of treatments intended to prevent or delay the onset of maladaptive correlates of aging in human beings. This journal is indexed on PubMed Central, MedLine, CAS, Scopus and the Elsevier
Bibliographic databases. The manuscript management system is completely online and includes a very quick and fair peer-review system, which is all easy to use. Visit http://www.dovepress.com/ testimonials.php to read real quotes from published authors. 